\title{
Research of Laser Marking and Engraving on Brass Alloy 260
}

\author{
Dainis Klavins \\ Faculty of Engineering \\ Rezekne Academy of Technologies \\ Rēzekne, Latvia \\ dainis.klavins@rta.lv \\ Ritvars Revalds \\ Faculty of Engineering \\ Rezekne Academy of Technologies \\ Rēzekne, Latvia \\ ritvars.revalds@rta.lv
}

\author{
Lyubomir Lazov \\ Faculty of Engineering \\ Rezekne Academy of Technologies \\ Rēzekne, Latvia \\ lyubomir.lazov@rta.lv \\ Edgars Zaicevs \\ Faculty of Engineering \\ Rezekne Academy of Technologies \\ Rēzekne, Latvia \\ edgars.zaicevs@rta.lv
}

\author{
Antons Pacejs \\ Faculty of Engineering \\ Rezekne Academy of Technologies \\ Rēzekne, Latvia \\ antons.pacejs@rta.lv
}

Abstract - Brass Alloy 260 is widely used in mechanical engineering (odometer contacts, radiator cores), electrical engineering (electrical connectors, screw shells), plumbing (bathroom fixtures), consumers (watch parts, buttons, lamps) etc. The paper presents an analysis of the laser marking and engraving process. The ability Rofin powerline f20 laser system to engrave on Brass Alloy 260 is described. Recommendations are given on choosing the right parameters for laser marking and engraving of Brass Alloy 260 products.

Keywords - laser engraving, laser marking, Brass Alloy 260, Brass Alloy laser marking, laser marking analysis.

\section{INTRODUCTION}

The need for different types of information to be placed on different products has increased in recent years. The most common information on products is related to the manufacturer. A serial number of the product or item, information about the manufacturer, manufacturer's logo, etc. Specific material for marking is brass alloy which is widely used in many areas including military area, where the need for marking has increased. Ammunition marking is necessary for public safety and stronger ammunition control. [2],[4]

Information can be placed in direct text (letters, numbers, and images) or encrypted (barcode or QR code). Different marking methods are used based on the type of material used and production needs. Manufacturing companies devote their efforts and resources to the development of different marking methods for specific needs.

Various marking methods are widely used in industries and fields: shock-mechanical; electro erosion; electrochemical; screen printing; pad printing; anodizing; thermal painting; powder coating; ink printing; labeling; laser marking etc. Each of them has its own place in different specific productions. As the materials used in production change, the requirements for their marking change.

Historically used marking methods become unprofitable or unusable. Like shock-mechanical marking method can't be used on brittle materials.[1] Laser marking successfully replace older marking methods and provide the following benefits:

- the ability to mark various types of materials - metals, semiconductors and dielectrics;

- contactless method;

- minimal heat-affected zone;

- high wear resistance;

- accuracy;

- high contrast;

- high labor productivity;

- high information density;

- flexibility; marking of hard-to-reach places;

- no additional processing;

- the possibility of marking in the movement; integration into automated lines;

- ensuring high protection of information; environmentally friendly process.

- possibility of marking on assembled products, like ammunition cartridges (Fig.1). [5], [6]

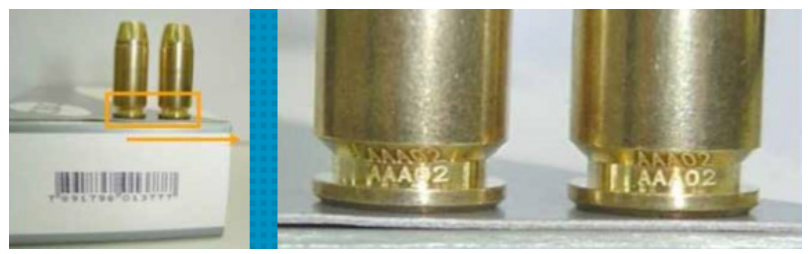

Fig. 1. Brass ammunition cartridge laser marking. [2]

As we have many different materials used in production, we must choose the right laser system that meets our marking needs. There are different types of laser systems on the market that have a wide range of applications:

- Gas laser - Helium-Neon, Argon, Krypton, Carbon dioxide, Nitrogen.

- Solid-state laser - Rubin, Neodymium: Glass, Neodymium, Alexandrite.

- Diode laser - GaAlAs/GaAs, InGaAsP/InP, InGaAlAs. [3] 


\section{OBJECTIVE OF THE STUDY}

The objective of the paper is to analyze marking possibilities on Brass Alloy 260 using the $20 \mathrm{~W}$ fiber laser system Rofin powerline $f 20$.

Research is made for company that manufactures several types of Brass Alloy 260 products. Goal is to create a system and marking technology and integrate it in one of the production stages with the following requirements:

- The mark should be clear and legible;

-After chemical treatment, the mark can't be significantly damaged;

-The marking area is up to $10 \times 50 \mathrm{~mm}$;

-Up to 16 symbols are placed in the marking area;

-Marking speed should be at least 2 products per second.

\section{MATERIALS AND EQUIPMENT}

\section{A. MATHERIALS}

Brass alloy has been used for many centuries for locks, plumbing valves (Fig.2), bearings and musical instruments. [A7]. Brass is an alloy of copper and zinc. Changes in proportions of zinc and copper leads to different material properties.

There are 3 types of commonly used brass alloys:

- Cartridge Brass (Brass alloy 260)-areas of application: plumbing tools, automotive manufacturing, ammunition (Fig.1) components etc.

- Brass C330 - wide usage in plumbing for good bending and welding ability.

- Brass C360 - Leaded brasses are known for resistance to atmospheric corrosion. [A7]

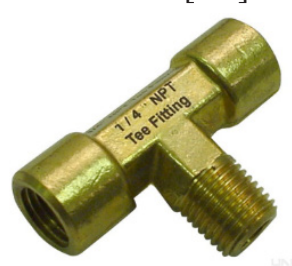

Fig. 2. Brass Laser Marking with Fiber Laser [A8]

Brass alloy 260 consist of copper and zinc. Where Coper is approx. 70\%, zinc is approx. $30 \%$ and other components are less than $0.15 \%$.

TABLE I. Component Elements Properties [A9]

\begin{tabular}{|l|l|}
\hline Copper, $\mathrm{Cu}$ & $68.5-71.5 \%$ \\
\hline Iron, $\mathrm{Fe}$ & $<=0.050 \%$ \\
\hline Lead, $\mathrm{Pb}$ & $<=0.070 \%$ \\
\hline Other, total & $<=0.15 \%$ \\
\hline Zinc, $\mathrm{Zn}$ & $28.5-31.5 \%$ \\
\hline
\end{tabular}

Brass alloy is a highly reflective material. Therefore, many laser systems are not suitable for marking this material (Fig.3).

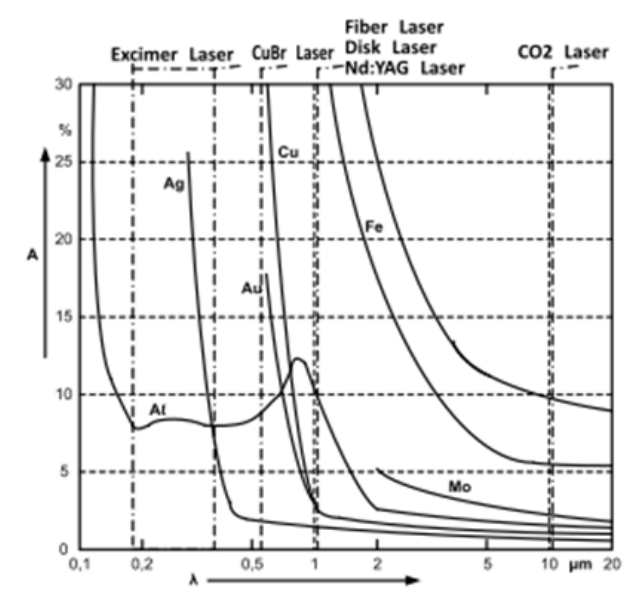

Fig. 3. Various material electromagnetic radiation absobrtion [\%] depending on emited wavelength $[\mu \mathrm{m}]$.

\section{B. LASER SYSTEM}

The fiber laser system Rofin powerline $f 20$ was used in the study.

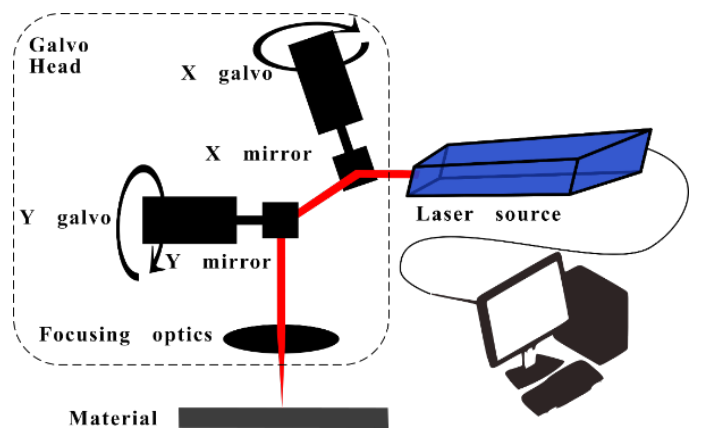

Fig. 4. Schematic view of Rofin powerline $f 20$ experimental set-up

Rofin powerline $f 20$ laser system technical parameters can be observed in Table II. and schematic view of experimental set-up could be observed in Fig. 4

TABLE II. ROFIN POWERLINE F20 TECHNICAL PARAMETERS

\begin{tabular}{|l|l|l|l|}
\hline Symbol & Name & Values range & Units \\
\hline$v$ & Scan speed & $1-20000$ & $\mathrm{~mm} / \mathrm{s}$ \\
\hline$\Delta \mathrm{f}$ & Defocus & $-10-+10$ & $\mathrm{~mm}$ \\
\hline$P$ & Avarege power & $0-20$ & $\mathrm{~W}$ \\
\hline$f$ & $\begin{array}{l}\text { Impulse frequen- } \\
\text { cy }\end{array}$ & $20-50$ & $\mathrm{kHz}$ \\
\hline$\tau$ & Impulse length & $4-200$ & $\mathrm{~ns}$ \\
\hline & Working range & $300 \mathrm{x} 300$ & $\mathrm{~mm}$ \\
\hline & Focal spot size & 20 & $\mu \mathrm{m}$ \\
\hline$\lambda$ & Wavelength & 1064 & $\mathrm{~nm}$ \\
\hline Laser type & & diode pumped fiber $\mathrm{Yb} ;$ \\
\hline Operating mode & impulse \\
\hline
\end{tabular}

\section{MESUREMENT DEVICES}

In the beginning of experiments laser system adjustments were made in pulse mode. The average output power was measured on an OPHIR F150A-BB-26 instrument (Table 3). Results are represented as power as a function from $\mathrm{k}_{\mathrm{p}}$ (Fig5). This graph is important as in laser system software must be defined coefficient $\mathrm{k}_{\mathrm{p}}$ not power directly. 
TABLE III

Power Measurement Sensor Ophir F150ABB-26 SPECIFICATIONS

\begin{tabular}{|l|l|}
\hline Absorber Type & Broadband \\
\hline Spectral Range $[\mu \mathrm{m}]$ & $0.19-20$ \\
\hline Aperture diameter $[\mathrm{mm}]$ & 26 \\
\hline Power Range $[\mathrm{W}]$ & $0,05-150$ \\
\hline Power Noise Level $[\mathrm{mW}]$ & 3 \\
\hline $\begin{array}{l}\text { Max Average Power Density } \\
{[\mathrm{kW} / \mathrm{cm} 2]}\end{array}$ & 12 \\
\hline Max Energy Desnity $[\mathrm{J} / \mathrm{cm} 2]$ & 10 \\
\hline Power Accuracy $[+/-\%]$ & 3 \\
\hline Cooling & fan \\
\hline & \\
\hline
\end{tabular}

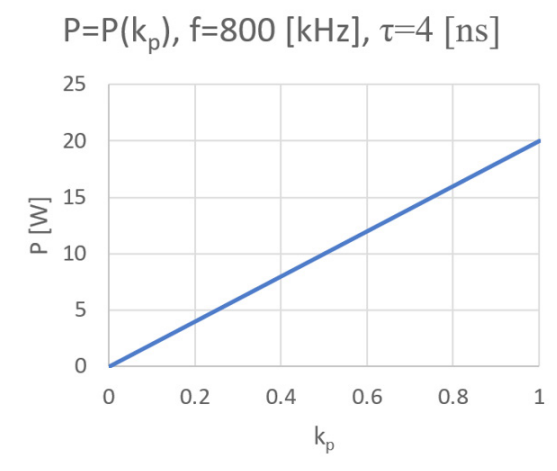

Fig. 5. Mapping of values of power regulation coefficient $\mathrm{k}_{\mathrm{p}}[\%]$ to laser mean power $\mathrm{P}[\mathrm{W}]$ with a constant pulse repetition frequency $\mathrm{f}=800[\mathrm{kHz}]$.

"Lext” 3D Laser Measuring Microscope OLS 5000 was used in this study for laser processing impact on the material e.g. in this case after laser processing we measured the width and depth of laser beam influence on the material.

Measurements were made using MPLFNN10XLEXT lens with 236x zoom and following technical data was given from manufacturer:

- $\quad \mathrm{Z}$ measurement pitch: $2 \mu \mathrm{m}$

- $\mathrm{Z}$ axis measurement accuracy: $0.15+\mathrm{L} / 20 \mu \mathrm{m}$

- $\mathrm{X}$ and $\mathrm{Y}$ axis resolution: $+/-1.5 \%$

\section{METHODS OF MEASUREMENT}

Effects on area of laser impact - heating, melting or evaporation depends on the energy that is absorbed by material. For understanding Energy absorption in more detail following formulas was used:

- Linear Pulse Energy

$$
L P E=\frac{P}{v},[J / m m]
$$

The LPE dimension is numerically equal to the absorbed energy per unit length in the laser marking area.

- Linear Pulse Density

$$
L P D=\frac{f}{v},
$$

The LPD dimension is numerically equal to the number of pulses fallen to a unit length.

- Effective energy
$\mathrm{E}_{\mathrm{ef}}=\mathrm{LPE}$ LPD,

The $E_{e f}$ dimension gives the amount of absorbed energy of the laser radiation per unit area of the laser impact area. From formulas (1), (2) and (3) formula a shorter version could be obtained (4).

$$
E_{e f}=\frac{P f}{v^{2}}
$$

\section{RESULTS AND DISCUSSIONS}

The experiments in this study were grouped in three main directions:

- Investigation of the duration of laser pulses on the width and depth of the lines marked on the samples;

- Investigation of the effect of the processing speed on the geometry of the marked line (width, depth);

- Examination of the influence of the power density on the marking (width and line depth)

During each of these series of experiments, the remaining technological parameters were kept constant.

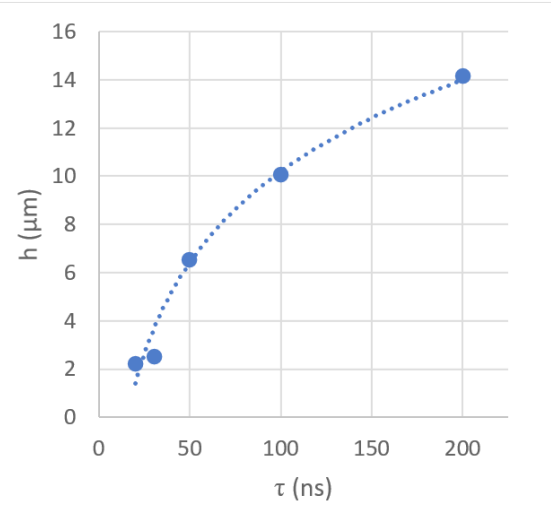

Fig. 6. Graph shows depth changes as a function from impulse length $\mathrm{h}=\mathrm{h}(\tau)$. Variable parameter is $\tau$. All other parameters are constant: $\mathrm{f}=2$ $[\mathrm{kHz}], \mathrm{k}_{\mathrm{p}}=80[\%], \mathrm{v}=20[\mathrm{~mm} / \mathrm{s}] . \mathrm{k}_{\mathrm{p}}$ - mean power [\%]; $\tau$ - pulse duration $[\mathrm{ns}] ; \mathrm{f}-$ pulse frequency $[\mathrm{kHz}] ; \mathrm{v}$ - marking speed $[\mathrm{mm} / \mathrm{s}]$

A nonlinear increase in the depth of the mark is observed for the entire investigated pulse duration range (Fig.6). The curve is part of a parabola. The rate of increase in depth is:

- $0.10 \mu \mathrm{m} / \mathrm{ns}$ for the range $\tau \in[20,100] \mathrm{ns}$;

- $\quad 0.04 \mu \mathrm{m} / \mathrm{ns}$ for the range $\tau \in[100,200] \mathrm{ns}$.

In the first pulse duration range, the marking depth is changing significantly faster than in the second. 


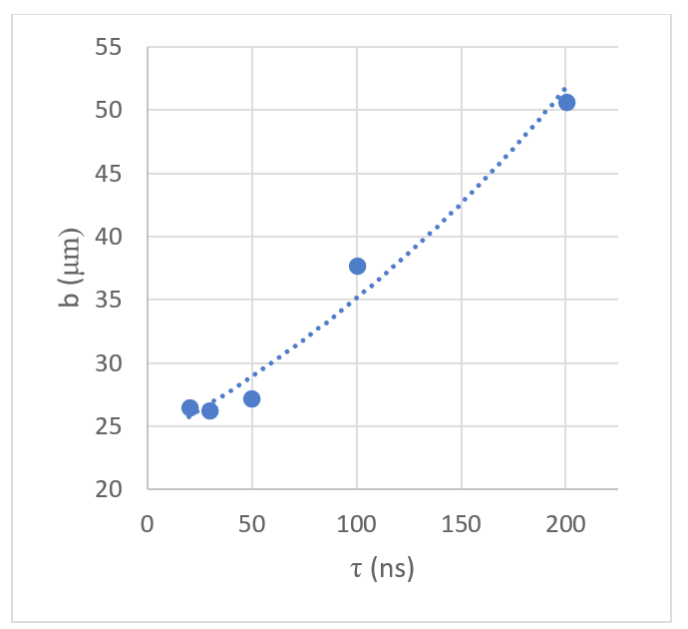

Fig. 7. Graph shows width changes as a function from impulse length $\mathrm{b}=\mathrm{b}(\tau)$. Variable parameter is $\tau$. All other parameters are constant: $\mathrm{f}=2[\mathrm{kHz}], \mathrm{k}_{\mathrm{p}}=80[\%], \mathrm{v}=20[\mathrm{~mm} / \mathrm{s}]$

A nonlinear increase in the width of the mark is observed for the entire investigated pulse duration range (Fig. 7). The curve is part of a concave parabola. The rate of increase in width is:

- $0.023 \mu \mathrm{m} / \mathrm{ns}$ for the range $\tau \in[20,50] \mathrm{ns}$

- $\quad 0.13 \mu \mathrm{m} / \mathrm{ns}$ for the range $\tau \in[50,200] \mathrm{ns}$.

In the first pulse duration range, the marking width is changing significantly faster than in the second.

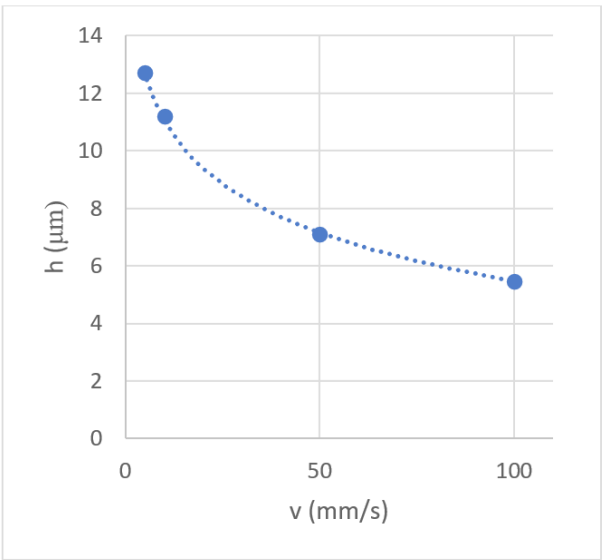

Fig. 8. Graph shows depth changes as a function from marking speed $\mathrm{h}=\mathrm{h}(\mathrm{v})$. Variable parameter is $\tau$. All other parameters are constant: $\mathrm{f}=2[\mathrm{kHz}], \mathrm{k}_{\mathrm{P}}=80[\%], \tau=200[\mathrm{~ns}]$.

The depth of the marking decreases non-linearly with increasing the span speed v $\in[5,100] \mathrm{mm} / \mathrm{s}$ (Fig.8). The rate of decrease in depth is:

- $0.139 \mu \mathrm{m} /(\mathrm{mm} / \mathrm{s})$ for the range $v \in[5,50]$ $\mathrm{mm} / \mathrm{s}$;

- $\quad 0.026 \mu \mathrm{m} /(\mathrm{mm} / \mathrm{s})$ for the range $v \in[50,100]$ $\mathrm{mm} / \mathrm{s}$.

The results are in line with the theory of speed influence on the laser marking process of metals.

The same non-linearity is observed for marking width changes as a function from marking speed (Fig.9).

The rate of decrease in width is:
- $0.93 \mu \mathrm{m} /(\mathrm{mm} / \mathrm{s})$ for the range $v \in[5,50]$ $\mathrm{mm} / \mathrm{s}$;

- $0.033 \mu \mathrm{m} /(\mathrm{mm} / \mathrm{s})$ for the range $v \in[50,100]$ $\mathrm{mm} / \mathrm{s}$.

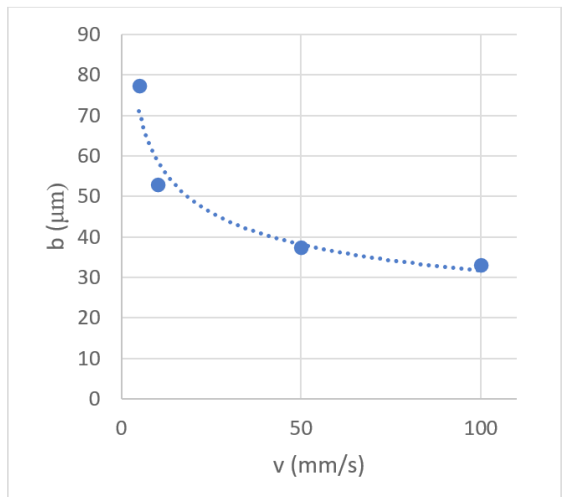

Fig. 9. Graph shows width changes as a function from marking speed $b=b(v)$. Variable parameter is $\tau$. All other parameters are constant: $\mathrm{f}=2[\mathrm{kHz}], \mathrm{k}_{\mathrm{p}}=80[\%], \tau=200[\mathrm{~ns}]$.

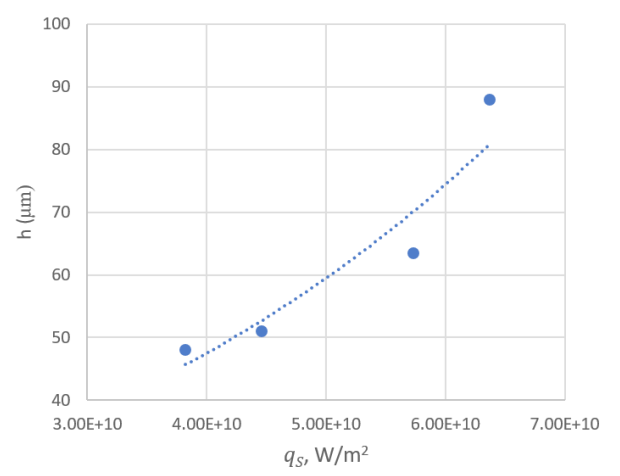

Fig. 10. Graph shows depth changes as a function from power density $\mathrm{h}=\mathrm{h}\left(\mathrm{q}_{\mathrm{S}}\right)$. All other parameters are constant: $\mathrm{f}=2[\mathrm{kHz}], \mathrm{v}=5$ $[\mathrm{mm} / \mathrm{s}], \tau=200[\mathrm{~ns}]$.

A nonlinear increase in the depth of the mark is observed for the entire investigated power density range (Fig.10).

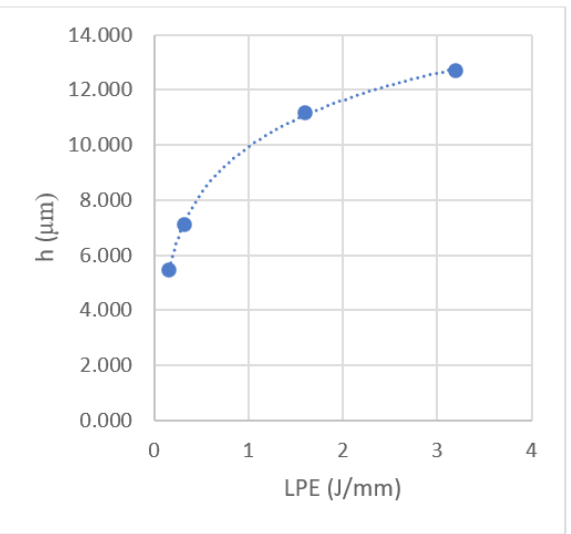

Fig. 11. Graph shows depth changes as a function from linear pulse energy. All other parameters are constant: $\mathrm{f}=2[\mathrm{kHz}], \mathrm{v}=5$ $[\mathrm{mm} / \mathrm{s}], \tau=200[\mathrm{~ns}], \mathrm{P}=18[\mathrm{~W}]$.

A nonlinear increase in the depth of the mark is observed for the entire investigated linear pulse energy 
range (Fig.11). The rate of increase in depth is:

- $3.984 \mu \mathrm{m} /(\mathrm{J} / \mathrm{mm})$ for the range LPE $\in[0.16$, 1.6] $\mathrm{J} / \mathrm{mm}$;

- $\quad 0.925 \mu \mathrm{m} /(\mathrm{J} / \mathrm{mm})$ for the range $\operatorname{LPE} \in[1.6,3.2]$ $\mathrm{J} / \mathrm{mm}$.

In the first pulse duration range, the marking depth is changing significantly faster than in the second.

\section{CONCLUSION}

More and more companies and manufacturers need to mark new materials where classical marking methods become more difficult to apply. Laser marking provides new opportunities to process different materials. Each material has its own specific characteristics, so it is necessary for each technology to choose the most optimal and efficient laser system.

The need for our research is new requirements for the manufacturer to mark each product by including the marking system in the production line. The material used in the production is Brass Alloy 260.

With our chosen F20 fiber laser system, samples with variable parameters of the laser system were marked. The depth and width of the mark were analyzed.

The depth and width of the marking lines were analyzed as a function of the laser parameters, the results obtained were good and meet the user requirements.

Further research will focus on analyzing other parameters related to markup quality, such as contrast, and more. Their dependence on changing laser parameters. Research will also be done with other laser systems having a variable wavelength. It will also assess the performance and economic efficiency of the new technology.

\section{REFERENCES}

[1]. "Great Impressions. Ruger turns to lasers to make its mark", Shot Business Daily, Day 2, January 16, 2013. www.telesis.com/pdf/shotdaily 22013 Ruger TTI Article.pdf

[2]. "Ammunition Control Practicies in Latin America and the Caribbean", UNLIREC, 2018.

http://www.unlirec.org/Documents/Amm Contro Practices.pdf

[3]. CO2 Laser, Technical documentation, TRUMPF $02 / 2007$

http://www.iconmachinetool.com/education/Library Laser CO2 Laser.pdf

[4]. Giacomo Persi Paoli, Ammunition Marking, Small Arms Survey Issue Brief, Number 3, December 2012

http://www.smallarmssurvey.org/fileadmin/docs/G-Issue-briefs/SAS-IB3-Ammunition-Marking.pdf

[5]. L. Lazov, N. Angelov, Principal factors determining quality of markings on metals and alloys. International Scientific Conference AMTECH- 2007, Gabrovo, Vol. I (2007) 102-10].

[6]. L. Lazov, H. Deneva, P. Narica, Laser Marking Methods. Environment. Technology. Resources, Rezekne, Latvia Proceedings of the 10th International Scientific and Practical Conference. 2015. Volume I, 108-115. 